\title{
Primary validation of Charm II tests for the detection of antimicrobial residues in a range of aquaculture fish
}

\author{
Aziz Kimera Mukota', Melanie Flore Kamini Gondam², Julie Judith Takadong Tsafack², James Sasanya ${ }^{3}$, \\ Wim Reybroeck ${ }^{4}$, Muhammad Ntale ${ }^{5}$, Steven Allan Nyanzi ${ }^{5}$ and Emmanuel Tebandeke ${ }^{5^{*}}$
}

\begin{abstract}
The study carried out a primary validation of Charm II tests for the detection of antimicrobial residues in aquaculture fish. The validation was performed according to European Commission Decision 2002/657/EC and the parameters determined included: detection capability, repeatability, reproducibility, specificity and robustness for the detection of antimicrobial residues in fish. Fish materials from different species including cat fish, trout, salmon, sea bass, tilapia, lingue and pangasius, were spiked with varying concentrations of selected antimicrobials including sulfonamides, $\beta$-lactams, macrolides, tetracyclines and aminoglycosides to determine the detection capabilities and other validation parameters of the Charm II tests. Results of the validation showed that the detection capabilities for the tetracyclines ranged from 25 to $100 \mu \mathrm{g} / \mathrm{kg}$, while the sulfonamides and aminoglycosides were detected at $25 \mu \mathrm{g} / \mathrm{kg}$ for all species under study. The detection capabilities for the beta-lactams ranged from 25 to $300 \mu \mathrm{g} / \mathrm{kg}$; and was $100 \mu \mathrm{g} / \mathrm{kg}$ for the tested macrolides. Results of the study showed that there was no significant difference between counts for samples read immediately after addition of the scintillation liquid and those read $14 \mathrm{~h}$ after addition of the scintillation liquid, provided that there was good vortexing before analysis. There was also no significant difference between counts for the same samples analyzed in different runs under repeatability and reproducibility conditions at the same spiking concentrations for the different fish species analyzed. The relative standard deviation for both repeatability and reproducibility ranged from 1.2 to $15.1 \%$. The Charm II tests were found to be $100 \%$ group specific, as none of the antimicrobials kits, gave false positive results when testing non-target antimicrobial drugs. Results of this study demonstrate the suitability of the Charm II technique as a rapid screening tool for detection of antimicrobial residues in a variety of fish species at maximum residue limits (MRL) established in the EU guidelines, with the exception of tilmicosin which was detected at $2 \mathrm{MRL}$. The results also prove the robustness, specificity, reliability and precision of the Charm II assay in the detection of various antimicrobial residuals in fish and its applicability for the rapid evaluation of the quality of aquaculture fish for safety and trade purposes.
\end{abstract}

Keywords: Charm II tests, Antimicrobial residues, Rapid screening, Method validation, Aquaculture fish, Maximum residue limit

*Correspondence: emmanuel@cns.mak.ac.ug

${ }^{5}$ Department of Chemistry, College of Natural Sciences, Makerere

University, P.O. Box, 7062, Kampala, Uganda

Full list of author information is available at the end of the article

\begin{abstract}
Introduction
Fish farming is a fast emerging industry that besides creating employment, is a source of good quality animal protein and essential macronutrients in the diet. Fish and fish related products provide income and livelihoods for numerous communities across the world besides playing
\end{abstract}

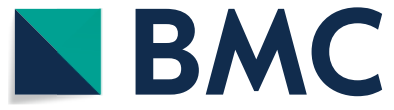

(c) The Author(s) 2020. This article is licensed under a Creative Commons Attribution 4.0 International License, which permits use, sharing, adaptation, distribution and reproduction in any medium or format, as long as you give appropriate credit to the original author(s) and the source, provide a link to the Creative Commons licence, and indicate if changes were made. The images or other third party material in this article are included in the article's Creative Commons licence, unless indicated otherwise in a credit line to the material. If material is not included in the article's Creative Commons licence and your intended use is not permitted by statutory regulation or exceeds the permitted use, you will need to obtain permission directly from the copyright holder. To view a copy of this licence, visit http://creativeco mmons.org/licenses/by/4.0/. The Creative Commons Public Domain Dedication waiver (http://creativecommons.org/publicdomain/ zero/1.0/) applies to the data made available in this article, unless otherwise stated in a credit line to the data. 
a crucial role in assuring sufficient availability of safe and healthy food $[1,2]$. The increased demand for fish for the growing international population, especially in the developing world, has continued to deplete the sustainable yields from lakes, rivers, swamps, seas and other natural water bodies. Aquaculture is growing rapidly and is seen as a remedy to address and supplement the dwindling quantities and shortfall in wild catch [3]. However, big numbers of fish in a confined volume of space tend to increase incidences of bacterial infections and other diseases; which greatly affects yield in the aquaculture business. Productivity in aquaculture may be enhanced by use of antimicrobials such as tetracyclines, macrolides, beta-lactams, sulfonamides, and streptomycins, for the prevention and treatment of opportunistic infections in fish $[4,5]$.

Antimicrobials are used to control ectoparasitic, fungal and bacterial diseases of the body and gills of fish [6-8]. Tetracyclines in particular are frequently employed in aquaculture due to their broad spectrum of activity as well as their low cost, compared to other antibiotics. The tetracyclines are used to combat bacterial hemorrhagic septicemia in catfish as well as diseases caused by Pseudomonas liquefaciens [9]. Currently, there are over 20 tetracyclines available; although, tetracycline, chlortetracycline, oxytetracycline, and doxycycline are the most common ones in veterinary medicine and aquaculture $[10,11]$. The aforementioned antibiotics are the only tetracyclines with registration within the European Union (EU) for use as veterinary medicinal products in food producing animals; with established maximum residue limits (MRLs) in different food matrices [12]. Other antimicrobials such as sulfonamides, beta-lactams, macrolides and aminoglycosides also have a wide spectrum of activities against most Gram positive and Gram negative organisms and are used for the prevention and treatment of bacterial infections in livestock and aquaculture. The antimicrobials are typically administered in the water, often as components of fish feed, and are occasionally injected $[13,14]$.

The extensive use and misuse of antimicrobials in farm animals as growth promoters or as nonspecific means of infection prevention has been reported to lead to accumulation of residues in edible tissue $[7,15,16]$; which may cause allergic and toxic effects in consumers as well as contributing to the development of antimicrobial resistant bacteria [17-20]. In this respect, residues in foodstuffs create public health concerns, consumer perception problems and trade disputes that have enormous negative impacts on the food industry. In order to protect human health, regulatory authorities like the EU, established maximum residue limits (MRLs) for some pharmaceutical compounds in fish and other foodstuffs of animal origin [12]. The safety concerns regarding drug residues in various food products, calls for development and validation of rapid and reliable techniques for detection of these compounds. Such rapid techniques can facilitate fast decision making to minimize technical barriers to trade and also enhance routine monitoring in order to protect consumer health.

The Charm II radio receptor assay technique developed by Charm Sciences Inc, is one of the rapid screening techniques for detection of residues of antimicrobials such as beta-lactams, sulfonamides, tetracyclines, chloramphenicol, quinolones, macrolides and aminoglycosides in various food products including fish, meat, eggs, honey, and milk, as well as non-food matrices including water, feed and urine. This technique utilizes a microbial cell with receptor sites that bind the specific antimicrobial drug. The analytical process involves a binder being added to a sample extract along with an amount of ${ }^{3} \mathrm{H}$ or ${ }^{14} \mathrm{C}$ labeled antimicrobial tracer. Any antimicrobial in the sample extract competes for the binding sites with the tracer. The amount of tracer that binds to the receptor sites is measured and compared to a previously determined control point. Therefore, the more radiolabelled antimicrobial detected in the mixture, the lower the concentration of antimicrobial in the sample. The smaller the amount of tracer measured, the greater the drug concentration in the sample [21, 22]. The Charm II technique has very limited validation data for the detection of antimicrobials in different fish species. Thus, this study conducted a primary validation of the Charm II tests in order to generate comprehensive analytical data to prove the validity, applicability and also address potential limitations of the Cham II assays particularly for the screening of antimicrobials in different aquaculture fish species.

\section{Materials and methods}

\section{Reagents, materials and equipment}

The antimicrobial test assay kit was obtained from Charm Sciences Inc., Lawrence, MA; and included items for the detection of beta-lactams (PMSU-050A); sulfonamides (SMMSU-022C), macrolides (EMSU-023A); tetracyclines (TMSU-025); and streptomycin (STMSU-023A). Consumables and equipment used for the tests included: M2 Buffer, zero and positive control standards, MSU extraction buffer, radioactive labelled tablets; scintillation fluid (Opti-Fluor O, PerkinElmer), Intronic incubator (Charm Sciences Inc.), Wallac 1409 scintillator counter, refrigerated centrifuge Sigma 4K15c (Sigma-Aldrich), R2 blender (Robot-Coupe) and a water bath (Julabo MB13). In addition, scintillation vials, AES mix masticator stomacher and IEC Centra CL-3 centrifuge were also used. 


\section{Preparation of standard reference material and stock solutions}

The multi antimicrobial concentrate standard (MSU, Charm Sciences Inc.) was prepared fresh on the day of use and diluted with $10 \mathrm{ml}$ of deionized water, shaken well and allowed to stand on ice for $15 \mathrm{~min}$. The reconstituted stock solution contained; penicillin G, $1000 \mu \mathrm{g} / \mathrm{kg}$; erythromycin A, 10,000 $\mu \mathrm{g} / \mathrm{kg}$; sulfamethazine, $1000 \mu \mathrm{g} /$ $\mathrm{kg}$; chlortetracycline, $4000 \mu \mathrm{g} / \mathrm{kg}$; and streptomycin, $10,000 \mu \mathrm{g} / \mathrm{kg}$. Other analytical standards were purchased from Sigma Aldrich, Pfizer Inc., US Pharmacopeia Convention and Acros Organics (Additional file 1: Table S1a). These standards were appropriately diluted with deionized water to make working standard solutions of the respective antimicrobial, and kept below $4{ }^{\circ} \mathrm{C}$. The working standards were used for spiking fish samples at different concentration levels ranging from 25 to $300 \mu \mathrm{g} / \mathrm{kg}$.

\section{Methods}

The study carried out a primary validation of the Charm II tests for the detection of antimicrobial residues in aquaculture fish. The validation was performed according to Commission Decision 2002/657/EC [23] and all methods of analysis used were adopted from the general Charm II protocols [21].

\section{Fish samples selected for the study}

The fish materials used in the study were obtained from dead fish purchased from Melle and Ghent fish shops and supermarkets in Belgium. Aquaculture fish species including cat fish (Siluriformes), trout (Oncorhynchus mykiss), salmon (Salmo salar), seabass (Dicentrarchus labrax), tilapia (Oreochromis niloticus), lingue (Molva molva), dorade (Sparus aurata) and pangasius (Pangasius bocourti), were selected for the study. Fish sample materials were taken by carefully removing the muscle tissue from the side of each fish taking precaution to exclude scales and skin. The fish samples that were not used immediately were stored below $-18^{\circ} \mathrm{C}$ for a maximum of 2 months.

\section{Sample preparation}

The fresh fish sample was weighed in a centrifuge tube and stored at $-18{ }^{\circ} \mathrm{C}$ until further processing. The frozen fish samples were thawed at $4{ }^{\circ} \mathrm{C}$ overnight and cut into small pieces before blending in a high speed blender. The blended fish material (10 g) was transferred into a polypropylene centrifuge tube and used immediately.

\section{Preparation of control samples}

All fish samples were first tested with the different Charm II kits and only used in case no veterinary drug residues was detected. Absence of residual antibiotics in the fish samples was confirmed through evaluation of their counts per minute in comparison with results obtained using the negative control extraction buffers supplied with the Charm II kits. The control buffers are contaminant free and are used to qualify the matrix as negative when a known negative is not available. The tolerance considered for the fish matrix to qualify as negative and selected for use in subsequent test was for counts within $\pm 20 \%$ of the average result obtained with the respective negative control extraction buffer. Samples with counts beyond the tolerance limits were discarded while those meeting the criteria were selected for the study. The selected blank fish materials after blending, were spiked with antimicrobial standards of known concentrations and used as control samples for the establishment of the control point counts per minute (cpm). A list of control standards used in the study is shown in Additional file 1: Table S1a.

\section{Extraction of drugs from the fish materials}

The MSU extraction buffer $(30 \mathrm{ml})$ was added to blended fish material $(10 \mathrm{~g})$ in a polypropylene centrifuge tube. The mixture was homogenized using a stomacher for $2 \mathrm{~min}$ and returned to the centrifuge tube. The homogenate was incubated in water bath at $80{ }^{\circ} \mathrm{C}$ for $30 \mathrm{~min}$, during the determination of streptomycin, macrolides, or beta-lactams; and $45 \mathrm{~min}$, when determining tetracyclines or sulfa drugs. After incubation, the tube was cooled on ice water for $10 \mathrm{~min}$ and then centrifuged at $3300 \mathrm{rpm}$ for $10 \mathrm{~min}$, using a refrigerated centrifuge 4K15C (Sigma-Aldrich). The resulting supernatant solution was collected and used for the required tests. The $\mathrm{pH}$ of the supernatant was where necessary adjusted to pH 7.5 using reconstituted Charm II kit M2 buffer for low $\mathrm{pH}$, or $0.1 \mathrm{M}$ hydrochloric acid for high $\mathrm{pH}$.

\section{Determination of tetracyclines in the fish samples}

In the detection of tetracycline, the white tablet from the kit containing the binding reagent (TMSU-025) was introduced into a test tube, and water $(300 \mu \mathrm{l})$ was added. The contents of the tube were mixed for at least $10 \mathrm{~s}$ to ensure breakup of the tablet. The sample extract or control sample $(4 \mathrm{ml})$ was added to the tube, followed by addition of the orange tablet containing the tracer reagent from the kit (TMSU-025). The resultant solution was mixed for about $10 \mathrm{~s}$ and the mixture was incubated at $35^{\circ} \mathrm{C}$ for $5 \mathrm{~min}$; and then centrifuged for another 5 min on a IEC Centra CL-3 centrifuge. The supernatant was poured off carefully, deterring the formed pellet from sliding out of test tube. Deionized water $(300 \mu \mathrm{l})$ was added to the tube and the contents mixed thoroughly to break up the pellet. After suspension of the pellet in 
water, the scintillation liquid $(3.0 \mathrm{ml})$ was added and test tube capped. The tube was shaken until the mixture had a uniform cloudy appearance. The glass tube contents were transferred completely into a scintillation vial and the mixture counted using a Wallac liquid scintillation counter for $60 \mathrm{~s}$ on the $\left[{ }^{3} \mathrm{H}\right]$ channel. The results for the sample was compared with the control point counts per minute.

\section{Determination of macrolides in the fish samples}

During the detection of macrolides, the white tablet from the Charm II kit containing the binding reagent (EMSU023A) was introduced into a test tube, and water $(300 \mu \mathrm{l})$ was added. The contents of the tube were mixed for at least $10 \mathrm{~s}$ to ensure breakup of the tablet. The sample extract or control sample $(4 \mathrm{ml})$ was added to the tube and the contents mixed on a vortex for $10 \mathrm{~s}$. The resultant was incubated at $55{ }^{\circ} \mathrm{C}$ for $2 \mathrm{~min}$, followed by addition of a green tablet containing the tracer reagent from the kit (EMSU-023A). The resultant was mixed on a vortex for $10 \mathrm{~s}$. The mixture was incubated at $55{ }^{\circ} \mathrm{C}$ for $2 \mathrm{~min}$, and then centrifuged for $5 \mathrm{~min}$. The supernatant was poured off carefully and the edge of tube blotted on absorbent paper. Deionized water $(300 \mu \mathrm{l})$ was added to the tube and the contents mixed thoroughly to break up the formed pellet. After suspension of the pellet in water, the scintillation liquid $(3.0 \mathrm{ml})$ was added and the test tube capped. The contents were mixed on a vortex until the mixture had a uniform cloudy appearance. The content of the glass tube was transferred completely into a scintillation vial and the mixture counted using a Wallac liquid scintillation counter for $60 \mathrm{~s}$ on the $\left[{ }^{14} \mathrm{C}\right]$ channel. The counts per minute (cpm) of the sample was compared with the control point.

\section{Determination of sulfa drugs in the fish samples}

In the detection of sulfa drugs, the white tablet from the Charm II kit containing the binding reagent (SMMSU022C) was introduced into a test tube, and water $(300 \mu \mathrm{l})$ added. The contents of the tube were mixed for at least $10 \mathrm{~s}$ to ensure breakup of the tablet. The sample extract or control sample $(4 \mathrm{ml})$ was added to the tube, followed by addition of the pink tablet containing the tracer reagent (SMMSU-022C) from the kit. The resultant solution was mixed by swirling the contents up and down for about $15 \mathrm{~s}$. The mixture was incubated at $65^{\circ} \mathrm{C}$ for $3 \mathrm{~min}$, and then centrifuged for another $3 \mathrm{~min}$. The supernatant was poured off carefully, deterring the formed pellet from sliding out of test tube; and the edge of tube was blotted on absorbent paper. Deionized water $(300 \mu \mathrm{l})$ was added to the tube and the contents mixed thoroughly to break up the pellet. After suspension of the pellet in water, the scintillation liquid $(3.0 \mathrm{ml})$ was added and test tube capped. The tube was shaken until the mixture had a uniform cloudy appearance. The glass tube contents were transferred completely into a scintillation vial and the mixture counted using a Wallac liquid scintillation counter for $60 \mathrm{~s}$ on the $\left[{ }^{3} \mathrm{H}\right]$ channel. The cpm results of the sample were compared with the control point.

\section{Determination of aminoglycoside-streptomycin in the fish samples}

In the determination of streptomycin, the white tablet from the kit containing the binding reagent (STMSU023A) was introduced into a test tube, and water $(300 \mu \mathrm{l})$ added. The contents of the tube were mixed for at least $10 \mathrm{~s}$ to ensure breakup of the tablet. The sample extract or control sample $(2 \mathrm{ml})$ was added to the tube and mixed. This was followed by addition of the green tablet containing the tracer reagent (STMSU-023A). The resultant was mixed by swirling the contents up and down for about $10 \mathrm{~s}$. The mixture was incubated at $35^{\circ} \mathrm{C}$ for $2 \mathrm{~min}$, and then centrifuged for another $3 \mathrm{~min}$. The supernatant was poured off carefully and the edge of tube was blotted with absorbent paper. Deionized water $(300 \mu \mathrm{l})$ was added to the tube and the contents mixed thoroughly. After suspension of the pellet in water, the scintillation liquid $(3.0 \mathrm{ml})$ was added and test tube capped. The tube was shaken until the mixture had a uniform cloudy appearance. The glass tube contents were transferred completely into a scintillation vial and the mixture counted using a Wallac liquid scintillation counter for $60 \mathrm{~s}$ on the $\left[{ }^{3} \mathrm{H}\right]$ channel. The cpm results for the sample were compared with the control point.

\section{Determination of $\beta$-lactams in the fish samples}

In the determination of $\beta$-lactams, the green tablet from the Charm II kit containing the binding reagent (PMSU050A) was introduced into a test tube, and water $(300 \mu \mathrm{l})$ was added. The contents of the tube were mixed to ensure breakup of the tablet. The sample extract or control $(2 \mathrm{ml})$ was added to the tube and the contents mixed on a vortex for $10 \mathrm{~s}$. The resultant was incubated at $55{ }^{\circ} \mathrm{C}$ for $2 \mathrm{~min}$, followed by addition of a yellow tablet containing the tracer reagent (PMSU-050A) from the kit. The resultant was mixed on a vortex for $10 \mathrm{~s}$. The mixture was incubated at $55{ }^{\circ} \mathrm{C}$ for $2 \mathrm{~min}$, and then centrifuged for $5 \mathrm{~min}$ at $1750 \mathrm{G}$. The supernatant was poured off carefully and the edge of tube blotted on absorbent paper. Deionized water $(300 \mu \mathrm{l})$ was added to the tube and the contents mixed thoroughly to break up the pellet. After suspension of the pellet in water, the scintillation liquid $(3.0 \mathrm{ml})$ was added and test tube capped. The contents were mixed on a vortex until the mixture had a uniform cloudy appearance. The mixture was transferred completely into a scintillation vial and counted using a Wallac 
liquid scintillation counter for $60 \mathrm{~s}$ on the $\left[{ }^{14} \mathrm{C}\right]$ channel. The cpm of the sample was compared with the control point.

\section{Method validation}

The method validation was done according to the criteria of the European Commission Decision 2002/657/ EC [23]. The validation parameters performed included; detection capability $(C C \beta)$, repeatability, reproducibility, robustness and cross reaction activity.

\section{Detection capability}

The CC $\beta$ was examined by spiking blank fish matrices with different antimicrobials including tetracyclines, macrolides, $\beta$-lactams, aminoglycosides, and sulfonamides. The number of samples analyzed for each individual antimicrobial agent ranged from 20 to 30 as indicated in Table 3. The spiking concentrations varied around the recommended maximum residue limit (MRL), including 0.05 MRL, 0.25 MRL, 0.5 MRL, 0.75 MRL and MRL, for the respective antimicrobial. The $\mathrm{CC} \beta$ was then determined as the lowest concentration of the antimicrobial that could be detected in the sample giving at least 95\% positive results.

\section{Repeatability}

The repeatability of the technique was studied by analysis of selected fish samples spiked with different antimicrobials including tetracyclines, macrolides, $\beta$-lactams, aminoglycosides, and sulfonamides. The total number of samples analyzed for each individual antimicrobial compound ranged from 20 to 30 , and $n \geq 6$ for the same fish species. The spiking concentrations varied around the MRL, including 0.05 MRL, 0.25 MRL, 0.5 MRL, 0.75 MRL and MRL, for the respective antimicrobial. The analysis was performed within a short interval, by a single researcher using the same method and scintillation fluid counter equipment.

\section{Reproducibility}

The reproducibility of the method was studied by repeat analysis of selected fish samples spiked with different antimicrobials including tetracyclines, macrolides, $\beta$-lactams, aminoglycosides, and sulfonamides. The number of samples analyzed for each individual antimicrobial ranged from 20 to 30 , with $n \geq 6$ for the same fish species. The spiking concentrations varied around the recommended MRL, including 0.05 MRL, 0.25 MRL, 0.5 MRL, $0.75 \mathrm{MRL}$ and MRL, for the respective antimicrobial. The analysis was performed on different days by two different researchers using the same method and a scintillation fluid counter equipment.

\section{Robustness}

The robustness of the techniques was tested by deliberately varying the experimental time indicated in the Charm II analytical protocol. This was intended to study the effect of variation in reading time interval for a large batch of processed samples. Reading of the cpm for the samples spiked with $50 \mu \mathrm{g} / \mathrm{kg}$ amoxicillin was done immediately after the addition of the scintillation liquid and then after $14 \mathrm{~h}$ on the same batch of extracted sample. The samples after the first reading were stored overnight in the fridge at $4{ }^{\circ} \mathrm{C}$, removed and allowed to attain room temperature, and then read the second time after vortexing.

\section{Cross reaction activity}

Cross reactivity was investigated by spiking residue-free blank fish samples with high concentrations (up to 10 MRL) of the respective antimicrobial belonging to other antimicrobial groups and the samples run on targeted channels to investigate false identification.

\section{Data Analysis}

All data generated was statistically analyzed using oneway analysis of variance (ANOVA) to examine any significant differences between the observed results under different experimental setups.

\section{Results and discussion}

\section{Counts per minute for blank samples}

The blank samples used in the study were those fish tissue matrices which were carried through the complete analytical procedure, and no antimicrobial residues were detected in them using the respective Charm II assay kits [21]. The blank fish samples to which the binder and tracer had been added but without addition of an antimicrobial agent were extracted with the different kits and read on the respective channels. The results of the cpm for the blank fish samples are summarized in Table 1.

From Table 1, the cpm for tilapia, trout, salmon, pangasius, seabass, dorate, catfish, and lingue fish species were statistically evaluated using ANOVA and it was found that the overall F-calculated (0.22) was less than F-critical (2.5), which implied that there was no significant difference between results for the blank fish samples of the aforementioned species when using antimicrobial test kits for $\beta$-lactams, tetracyclines, macrolides and streptomycins. However significant difference in cpm values was observed with the sulfonamides extraction kit while testing catfish, lingue and pangasius. The cpm for 
Table 1 Blank counts per minute for the different fish species obtained using the Charm II technique

\begin{tabular}{|c|c|c|c|c|c|c|c|c|c|c|}
\hline \multicolumn{11}{|c|}{ Scintillation counter results (cpm) } \\
\hline \multirow{2}{*}{$\begin{array}{l}\text { Charm II test } \\
\text { Fish species }\end{array}$} & \multicolumn{2}{|c|}{$\beta$-lactams kit } & \multicolumn{2}{|c|}{ Sulfonamides kit } & \multicolumn{2}{|c|}{ Tetracyclines kit } & \multicolumn{2}{|c|}{ Macrolides kit } & \multicolumn{2}{|c|}{ Streptomycins kit } \\
\hline & Mean & SD & Mean & SD & Mean & SD & Mean & SD & Mean & SD \\
\hline Tilapia & 2704 & 0.9 & 2596 & 736 & 3027 & 0.7 & 2448 & 191.1 & 5103 & 346 \\
\hline Trout & 2506 & 192.0 & 2332 & 1184 & 2830 & 260 & 2799 & 87.1 & 4799 & 259.9 \\
\hline Salmon & 2571 & 207.4 & 2472 & 541.2 & 2939 & 165.0 & 2110 & 117.2 & 3085 & 133.4 \\
\hline Pangasius & 2469 & 195.7 & 5625 & 1254 & 2931 & 221.4 & 2893 & 110 & 4796 & 437.7 \\
\hline Seabass & 2432 & 232.1 & 2144 & 672.1 & 2971 & 252.2 & 2700 & 153.6 & 4805 & 594.7 \\
\hline Dorate & 2512 & 171.1 & 1977 & 621.4 & 2864 & 93.4 & 2803 & 167.3 & 4967 & 485.8 \\
\hline Catfish & 2493 & 312.7 & 5872 & 774.3 & & & & & & \\
\hline Lingue & & & 4454 & 650.1 & & & & & & \\
\hline
\end{tabular}

cpm counts per minute, SD standard deviation

these species were almost double those of the other types of fish and their F-calculated (15.1) was greater than F-critical (2.4). The big variation in cpm for the catfish, lingue and pangasius fish species as compared to the rest could be attributed to the high fish fat content extracted by the sulfonamide kit protocol. In this respect, the three fish species (catfish, lingue and pangasius) need to be handled separately when calculating control points to minimize chances of getting false negative or false positive results. For the rest of the fish species, the blank cpm results were used to derive the respective control points for the different residues.

\section{Evaluation of the Control Points for the different drug residues}

The control point (CP) of a sample is the cut-off point between a negative or positive result. Any antimicrobial agent present in the sample extract competes for the binding sites with the tracer, thus, the greater the cpm measured, the lower the antimicrobial drug concentration in the sample and vice versa. Samples with high counts are considered negative (tracer antimicrobials are largely bound to the binder) while those with low counts are considered positive (tracer antimicrobials are largely free in solution). The CP for the different antimicrobials were determined independently; and with the exception of tetracyclines, the MRL value for each drug was spiked to the respective blank fish sample. In order to cater for the deviations in the different fish matrices, a percentage tolerance was added to or subtracted from the obtained average cpm value of the spiked blank fish sample. The CP evaluation was performed according to the Charm II protocol, and the percentages added to the mean value of spiked samples at detection capability or subtracted from the mean value of blanks serve to minimise occurrence of false positive or negative readings [21, 24, 25].
In this respect, the $\mathrm{CP}$ for the $\beta$-lactams was evaluated from averaging the results of 6 negative samples spiked with penicillin $\mathrm{G}$ at $25 \mu \mathrm{g} / \mathrm{kg}(0.5 \mathrm{MRL})$ and adding $20 \%$ of the obtained average cpm value. Whereas, for the sulfonamides, the CP was evaluated by averaging results of negative samples spiked at $50 \mu \mathrm{g} / \mathrm{kg}$ with sulfamethazine and adding $30 \%$ of the average obtained cpm value. A control point of 1530 was calculated for the $\beta$-lactams. On the other hand, the CP for tetracyclines was calculated by averaging cpm results of negative control standards provided in the tetracyclines test kit and subtracting $40 \%$ of the obtained average cpm value (Table 2 ).

For macrolides, the CP was derived from averaging the results of 6 negative samples spiked with erythromycin A at $100 \mu \mathrm{g} / \mathrm{kg}(0.5 \mathrm{MRL})$ and adding $20 \%$ of the obtained average cpm value. Using a similar approach, the CP for streptomycin was derived from averaging results of negative samples spiked at $25 \mu \mathrm{g} / \mathrm{kg}$ with streptomycin and adding $30 \%$ of the average obtained cpm value.

During the analysis of antimicrobial residues in fish samples, results less than or equal to each respective CP were interpreted as positive while those greater than the $\mathrm{CP}$, as negative. Blank sample readings below the set CP were considered false positive. The results in Table 2, show that the false positive rate was $0 \%$ for tetracyclines, $\beta$-lactams and sulfonamides; $3.6 \%$ for macrolides, and $5 \%$ for streptomycin; this proved the validity of the obtained data since it met the acceptance criteria of being within $5 \%$. A comparison of the CP for the different antimicrobials obtained using the Charm II assay with the corresponding cut-off points (Fm) and technical threshold (T) values, calculated following Annex II of the EU guideline for Community Reference Laboratories Residues for validation of screening methods [26], is shown in Table 3.

According to the EU guideline, the cut off factor (Fm), refers to the response or signal from a screening 
Table 2 Control points for the different antimicrobials in blank fish samples

\begin{tabular}{|c|c|c|c|c|c|c|c|c|}
\hline \multirow{2}{*}{$\begin{array}{l}\text { Antimicrobial } \\
\text { family }\end{array}$} & \multicolumn{4}{|l|}{ Spiked samples } & \multicolumn{4}{|c|}{ Blank samples } \\
\hline & $\begin{array}{l}\text { Level of analyte } \\
\text { spiking }(\mu \mathrm{g} / \mathrm{kg})\end{array}$ & $\begin{array}{l}\text { Mean cpm } \\
\text { of spiked } \\
\text { samples }\end{array}$ & $\begin{array}{l}\text { Allowance } \\
\text { for matrix } \\
\text { effect }\end{array}$ & $\begin{array}{l}\text { Control } \\
\text { point } \\
\text { cpm }\end{array}$ & $\begin{array}{l}\text { Mean blank } \\
\text { cpm }\end{array}$ & $\begin{array}{l}\text { Range of blank } \\
\text { cpm readings }\end{array}$ & $\begin{array}{l}\text { No. of false } \\
\text { positives/no. } \\
\text { of samples }\end{array}$ & $\begin{array}{l}\text { False } \\
\text { positive } \\
\text { rate (\%) }\end{array}$ \\
\hline$\beta$-lactams & $\begin{array}{l}25 \mu \mathrm{g} / \mathrm{kg} \text { penicil- } \\
\operatorname{lin} \mathrm{G}\end{array}$ & 1275 & $\begin{array}{l}\text { Spiked } \\
\quad c p m+20 \%\end{array}$ & 1530 & 2502 & $2160-2907$ & $0 / 30$ & 0 \\
\hline Sulfonamides & $\begin{array}{l}50 \mu \mathrm{\mu g} / \mathrm{kg} \text { sul- } \\
\text { famethazine }\end{array}$ & 1096 & $\begin{array}{l}\text { Spiked } \\
\quad \mathrm{cpm}+30 \%\end{array}$ & 1424 & 3162 & $1431-6995$ & $0 / 30$ & 0 \\
\hline Tetracyclines & $\begin{array}{l}0 \mu \mathrm{g} / \mathrm{kg} \text { tetracy- } \\
\text { cline }\end{array}$ & 2524 & $\begin{array}{c}\text { Blank cpm } \\
-40 \%\end{array}$ & 1514 & 2524 & $2451-3269$ & $0 / 30$ & 0 \\
\hline Macrolides & $\begin{array}{l}100 \mathrm{\mu g} / \mathrm{kg} \text { eryth- } \\
\text { romycin A }\end{array}$ & 1765 & $\begin{array}{l}\text { Spiked } \\
\quad c p m+20 \%\end{array}$ & 2118 & 2587 & $1906-2952$ & $1 / 28$ & 3.6 \\
\hline Streptomycin & $\begin{array}{l}25 \mu \mathrm{\mu g} / \mathrm{kg} \text { strep- } \\
\text { tomycin }\end{array}$ & 2574 & $\begin{array}{l}\text { Spiked } \\
\quad \text { cpm }+30 \%\end{array}$ & 3346 & 4605 & $2942-5488$ & $1 / 20$ & 5.0 \\
\hline \multicolumn{9}{|c|}{ Number of samples used per parameter $N s \geq 20$} \\
\hline
\end{tabular}

Table 3 Comparison of control points by Charm II protocol, cut-off points and technical threshold values calculated according to the EU guideline $[26,27]$

\begin{tabular}{|c|c|c|c|c|c|c|}
\hline $\begin{array}{l}\text { Antimicrobial } \\
\text { family }\end{array}$ & Compound & $\begin{array}{l}\text { Spiked } \\
\text { concentration } \\
(\mu \mathrm{g} / \mathrm{kg})\end{array}$ & $\begin{array}{l}\text { B average } \\
\text { response of blank } \\
\text { samples }\end{array}$ & $\begin{array}{l}\text { Calculated T value } \\
\text { as per EU guideline } \\
T=B-1.64 * S D b \\
{[26,27]}\end{array}$ & $\begin{array}{l}\text { Calculated Fm } \\
\text { value as per EU } \\
\text { guideline } \\
F m=M+1.64 * S D s \\
{[26,27]}\end{array}$ & $\begin{array}{l}\text { Calculated } \\
\text { control point CP } \\
\text { as per Charm II assay }\end{array}$ \\
\hline \multirow[t]{3}{*}{ Tetracyclines } & Tetracycline & 25 & 2958 & 2776 & 816 & 1514 \\
\hline & Chlortetracycline & 25 & 3050 & 2780 & 1417 & \\
\hline & Oxytetracycline & 100 & 2891 & 2579 & 1427 & \\
\hline \multirow[t]{3}{*}{ Macrolides } & Erythromycin A & 100 & 2814 & 2564 & 1904 & 2118 \\
\hline & Tilmicosin & 100 & 2486 & 2164 & 2002 & \\
\hline & Tylosin A & 100 & 2512 & 2115 & 1740 & \\
\hline \multirow[t]{6}{*}{$\beta$-Lactams } & Penicillin G & 25 & 2523 & 2176 & 1438 & 1530 \\
\hline & Ampicillin & 50 & 2455 & 2042 & 1341 & \\
\hline & Amoxicillin & 50 & 2702 & 2536 & 1487 & \\
\hline & Oxacillin & 300 & 2398 & 2171 & 1478 & \\
\hline & Dicloxacillin & 300 & 2524 & 2384 & 1489 & \\
\hline & Cloxacillin & 300 & 2500 & 2368 & 1413 & \\
\hline Aminoglycosides & Streptomycin & 25 & 4822 & 3867 & 2592 & 3346 \\
\hline \multirow[t]{5}{*}{ Sulfonamides } & Sulfamethazine & 25 & 2593 & 1428 & 1379 & 1424 \\
\hline & Sulfadimethoxine & 25 & 2266 & 1129 & 972 & \\
\hline & Sulfamerazine & 25 & 2210 & 1095 & 930 & \\
\hline & Sulfadiazine & 25 & 2297 & 1296 & 1184 & \\
\hline & Sulfathiazole & 25 & 2266 & 1643 & 1485 & \\
\hline
\end{tabular}

Cut-off factor $(\mathrm{Fm})=\mathrm{M}+1.64 * \mathrm{SD}$; Technical threshold $(\mathrm{T})=\mathrm{B}-1.64 * \mathrm{SDb} ; \mathrm{M}$, mean response of spiked samples; $\mathrm{B}$, mean response of blank samples; $\mathrm{SD}$, standard deviation of the spiked sample readings; $\mathrm{SDb}$, standard deviation of blank readings

test which indicates that a sample contains an analyte at or above the screening target concentration [26], while the Charm II protocol CP is the cut-off point between a negative or positive result [21]. On the other hand, the technical threshold (T), refers to the limit for positivity [26]. For the Charm II technique the readings of the blank samples are greater than those for spiked samples, because the responses are inversely proportional to concentrations of the antimicrobials. In this respect, the assay is considered valid only when $\mathrm{Fm}<\mathrm{T}$ and the $C C \beta$ is validated when $\mathrm{Fm}<\mathrm{B}$. Accordingly, the number of spiked samples with mean responses below 
the cut-off level (deemed positive) is identified and the false positive rate determined. If $\mathrm{T}<\mathrm{Fm}<\mathrm{B}$, the falsepositive rate is greater than $5 \%$. In the case $\mathrm{Fm}<\mathrm{T}$ the false positive rate is below $5 \%$. If more than $5 \%$ of the spiked samples at the screening target concentration gave a response greater than the cut-off level (deemed false negative), the concentration chosen for the spiking is considered too low for validation and a higher concentration is tested [26, 27].

From the results presented in Table 3, the Fm values obtained using the EU guideline and the respective calculated $\mathrm{CP}$ according to the Charm II protocol are comparable. For all antimicrobials, the respective CC $\beta$, presented in Table 3 are valid since in all cases the $\mathrm{Fm}<\mathrm{B}$. In addition, for all antibiotics involved in the study the $\mathrm{Fm}<\mathrm{T}$, which implies that the Charm II techniques is validated for the detection of antimicrobial residues in fish matrix, with a false positive rate of less than 5\%. In comparison with the Charm II protocol, it should be noted that in all cases the CP value for a particular family of antibiotics is slightly higher the corresponding Fm readings, with the exception of sulfathiazole. This suggests that there will be less incidences of false negative readings in the detection of the different antimicrobial compounds in fish matrix based on $\mathrm{CP}$ values, although this may increase incidences of false positive readings.

\section{Detection capability for the different antimicrobials} in selected fish species

The CC $\beta$ is the lowest concentration of the analyte that could be detected in the sample giving at least $95 \%$ positive results. In the $\mathrm{CC} \beta$ studies, blank negative fish tissue samples were spiked with different antimicrobials at various concentrations. Spiked samples that exhibited readings above the set $\mathrm{CP}$ value, were interpreted as false negatives. In case more than $5 \%$ of the spiked samples at a target concentration gave false negative readings, the concerned concentration was deemed too low for validation and a higher concentration was considered. A summary of the $C C \beta$ for the different drugs involved in the study is presented in Table 4. Results show that the Charm II technique can detect tetracycline and chlortetracycline spiked at $25 \mu \mathrm{g} / \mathrm{kg}(0.25 \mathrm{MRL})$ and oxytetracycline at $100 \mu \mathrm{g} / \mathrm{kg}$ (MRL) for the different fish species (cat fish, trout, salmon, seabass, tilapia, lingue, dorade, and pangasius) with $100 \%$ detection. However, the batch of the multiantimicrobial standard, provided in the Charm II kit was not sensitive enough for chlortetracycline to be detected at $100 \mu \mathrm{g} / \mathrm{kg}$ (MRL) level. This could be attributed to the deterioration of the chlortetracycline in the standard due to poor handling, probably during transportation. In this respect, a Sigma Aldrich standard was used and chlortetracycline detected at a concentration as low as $0.25 \mathrm{MRL}$. Interestingly, it was observed that the technique is also capable of detecting other antimicrobials belonging to the

Table 4 Detection capability for the selected antimicrobials

\begin{tabular}{|c|c|c|c|c|c|c|c|c|c|}
\hline \multirow[t]{2}{*}{ Family } & \multirow[t]{2}{*}{ Compound } & \multirow[t]{2}{*}{$\begin{array}{l}\text { EU-MRL } \\
(\mu \mathrm{g} / \mathrm{kg})\end{array}$} & \multirow[t]{2}{*}{$C C \beta(\mu \mathrm{g} / \mathrm{kg})$} & \multirow[t]{2}{*}{ No of samples } & \multirow{2}{*}{$\begin{array}{l}\text { No } \\
\text { of positive } \\
\text { samples }\end{array}$} & \multicolumn{3}{|c|}{$\begin{array}{l}\text { Counter results } \\
(\mathrm{cpm})\end{array}$} & \multirow{2}{*}{$\begin{array}{l}\% \text { Detection } \\
\text { of each } \\
\text { antimicrobial }\end{array}$} \\
\hline & & & & & & Mean & Min & Max & \\
\hline \multirow[t]{3}{*}{ Tetracyclines (CP = 1514 cpm) } & Tetracycline & 100 & 25 & 20 & 20 & 724 & 650 & 825 & 100 \\
\hline & Chlortetracycline & 100 & 25 & 21 & 21 & 1200 & 942 & 1421 & 100 \\
\hline & Oxytetracycline & 100 & 100 & 31 & 31 & 1269 & 1074 & 1460 & 100 \\
\hline \multirow[t]{3}{*}{ Macrolides (CP $=2118 \mathrm{cpm})$} & Erythromycin A & 200 & 100 & 30 & 30 & 1669 & 954 & 1955 & 100 \\
\hline & Tilmicosin & 50 & 100 & 21 & 21 & 1565 & 1221 & 2078 & 100 \\
\hline & Tylosin A & 100 & 100 & 21 & 21 & 1440 & 1103 & 1742 & 100 \\
\hline \multirow[t]{6}{*}{$\beta$-Lactams (CP $=1530 \mathrm{cpm})$} & Penicillin G & 50 & 25 & 22 & 22 & 1175 & 921 & 1421 & 100 \\
\hline & Ampicillin & 50 & 50 & 21 & 21 & 1055 & 837 & 1451 & 100 \\
\hline & Amoxicillin & 50 & 50 & 22 & 22 & 1132 & 908 & 1409 & 100 \\
\hline & Oxacillin & 300 & 300 & 24 & 24 & 1286 & 1082 & 1459 & 100 \\
\hline & Dicloxacillin & 300 & 300 & 22 & 21 & 1186 & 827 & 1839 & 95.5 \\
\hline & Cloxacillin & 300 & 300 & 20 & 19 & 1143 & 681 & 1547 & 95.0 \\
\hline Aminoglycosides (CP = 3346 cpm) & Streptomycin & 500 & 25 & 22 & 22 & 2424 & 1642 & 3074 & 100 \\
\hline \multirow[t]{5}{*}{ Sulfonamides (CP = 1424 cpm) } & Sulfamethazine & 100 & 25 & 29 & 28 & 1240 & 813 & 1831 & 96.6 \\
\hline & Sulfadimethoxine & 100 & 25 & 20 & 20 & 968 & 737 & 923 & 100 \\
\hline & Sulfamerazine & 100 & 25 & 21 & 21 & 842 & 716 & 960 & 100 \\
\hline & Sulfadiazine & 100 & 25 & 20 & 20 & 948 & 735 & 1361 & 100 \\
\hline & Sulfathiazole & 100 & 25 & 20 & 19 & 989 & 698 & 1782 & 95.0 \\
\hline
\end{tabular}


tetracycline family (tetracycline, oxytetracycline) and not limited to the chlortetracycline provided for in the Charm II test kit.

The sulfa drugs including, sulfadimethoxine, sulfadiazine, sulfamerazine were detected at $25 \mu \mathrm{g} / \mathrm{kg}(0.25 \mathrm{MRL})$ for the different fish species (trout, salmon, seabass, tilapia and dorade) at 100\% detection; sulfamethazine was detected at $25 \mu \mathrm{g} / \mathrm{kg}(0.25 \mathrm{MRL})$ at $96.6 \%$ detection (3.4\% false negatives), and sulfathiazole was detected at $25 \mu \mathrm{g} /$ $\mathrm{kg}(0.25 \mathrm{MRL})$ at $95.0 \%$ detection (5.0\% false negatives). The results also show that the technique can detect other antimicrobials belonging to the sulfonamides group (sulfamethazine, sulfadimethoxine, sulfamerazine, sulfadiazine and sulfathiazole), which are not included in the MSU multi-antimicrobial standard mix, provided in the Charm II test kit. For the macrolides; erythromycin A, tilmicosin, and tylosin A were detected at $100 \mu \mathrm{g} / \mathrm{kg}$, for the different fish species (cat fish, trout, salmon, seabass, tilapia, lingue, dorade, and pangasius) with 100\% detection. Whereas, results for the $\beta$-lactams show that penicillin G, ampicillin, amoxicillin, oxacillin, dicloxacillin and cloxacillin were detected at $25 \mu \mathrm{g} / \mathrm{kg}, 50 \mu \mathrm{g} / \mathrm{kg}$, $50 \mu \mathrm{g} / \mathrm{kg}, 300 \mu \mathrm{g} / \mathrm{kg}, 300 \mu \mathrm{g} / \mathrm{kg}$ and $300 \mu \mathrm{g} / \mathrm{kg}$ respectively, for all fish species involved in the study. Thus, penicillin $\mathrm{G}$ is detected at $0.5 \mathrm{MRL}$, whereas ampicillin, amoxicillin, oxacillin, dicloxacillin and cloxacillin are all detected at their respective MRL. However, 4.5 and $5 \%$ of the results for dicloxacillin and cloxacillin respectively, were false negatives (Table 4). Further more, the Charm II technique is capable of detecting streptomycin at $25 \mu \mathrm{g} / \mathrm{kg}(0.05 \mathrm{MRL})$ for all fish species involved in the study at $100 \%$ detection.

A comparison of the CC $\beta$ and MRL for the different antimicrobials is shown in Fig. 1 . The results show that, $\mathrm{CC} \beta$ for the validated antimicrobials were below or equal to the MRL for all drug residues in this study, with the exception of tilmicosin which was detected at 2 MRL. Most of the drug residues exhibited $C C \beta$ in the range $0.05 \mathrm{MRL}$ to $0.5 \mathrm{MRL}$, with $100 \%$ detection. Moreover, the incidences of false negative results observed for all

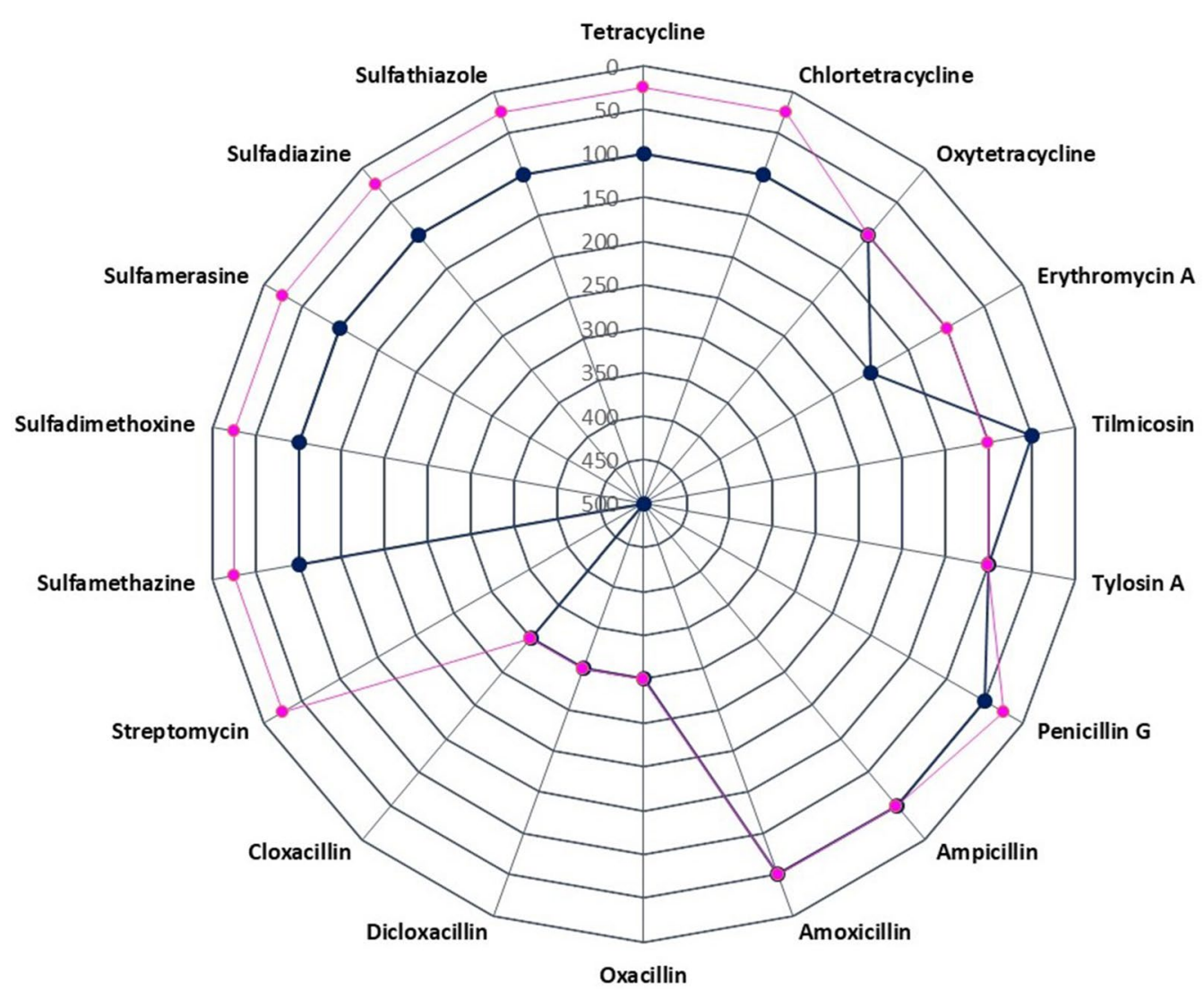

$\longrightarrow$ EU-MRL $(\mu \mathrm{g} / \mathrm{kg}) \quad \longrightarrow$ Detection capability CC $\beta(\mu \mathrm{g} / \mathrm{kg})$ of Charm II Technique

Fig. 1 The detection capabilities and maximum residue limits for the different antimicrobials 
antimicrobials involved in the study were within the $5 \%$ requirement of the EU decision 2002/657, and therefore the validation results are satisfactory. The Charm II technique exhibited better $C C \beta$ for tetracyclines at $25 \mathrm{ppb}$ (0.25 MRL) compared to other rapid screening techniques such as the ELISA kit of R-Biopharm for screening tetracycline antibiotic residues in the muscle of chicken, beef, and shrimp, which detected the same at $100 \mathrm{ppb}$ (MRL) [27]. In another study, results of the revolutionary Biochip Array Technology showed better detectability for tylosin A and oxytetracycline at 0.10 and 0.5 of the respective MRL in samples [28].

The limits of detection (LOD) obtained using the Charm Test II assays, and the limits of quantitation (LOQ) for selected literature chemical methods are presented in Additional file 1: Table S1b. The LOD results for fish matrix obtained in this validation using the Charm II kits, are comparable to the manufacturer's claims for the tissue matrix. However, some antimicrobial compounds could be detected in fish tissue at levels lower than the manufacturer's claim (Additional file 1: Table S1b). The LOD results were also compared with the LC-MS/MS analysis of sulfadimethoxine [29], HPLC-MS/MS analyses of tetracyclines, chlortetracycline, oxytetracycline, sulfadimethoxine, sulfamerazine and sulfadiazine [30]; and LC-ESI-MS/MS analyses of a range of tetracyclines, $\beta$-lactams, aminoglycosides and sulfonamides [31]. Generally, the rigorous chemical techniques, as expected, offer lower LOQ values compared to the respective LOD obtained with the Charm II tests. Nonetheless, the Charm II test demonstrated ability to detect a wider range of antimicrobials belonging to different classes including tetracyclines, macrolides, $\beta$-lactams, aminoglycosides and sulfonamides at MRL or lower levels, but it requires use of different antimicrobial test kits in parallel; unlike some of the chemical techniques that can simultaneously detect numerous antimicrobials $[30,31]$.

\section{Repeatability of the method}

Repeatability analysis was performed using the same Charm II protocol for a specific antimicrobial on different fish species performed by the same researcher. The analysis was evaluated by means of the intra-day coefficient of variations and the results are presented in Table 5 . Results of the repeatability study characterized by the relative standard deviation (\%RSD) were satisfactory with a precision of less than $12 \%$ for the different antimicrobial drugs including tetracyclines, macrolides, $\beta$-lactamss, aminoglycosides, and sulfonamides; spiked in blank fish samples at MRL, 0.5 MRL or concentration less than 0.5 MRL and analysed under repeatability conditions $(n \geq 6)$. The coefficient of variation expressed as percentage relative standard deviation $\left(\mathrm{RSD}_{\mathrm{r}}\right)$ ranged from 7.8 to $9.8 \%$ for tetracyclines (chlortetracycline and oxytetracycline), 2.8 to $6.3 \%$ for macrolides (erythromycin A), 6.9 to $9.7 \%$ for $\beta$-lactams (penicillin G), 10.01 to $11.5 \%$ for aminoglycosides (streptomycin); and for sulfonamides (sulfathiazole) it was from 1.2 to $8.7 \%$. These results, ably demonstrate the protocol's repeatability when used for testing different antimicrobial residues in fish tissue matrix.

A closer look at results obtained under repeatability conditions in the analysis of different fish samples spiked with $25 \mu \mathrm{g} / \mathrm{kg}$ sulfathiazole is presented in Table 6 . The results showed that there was no significant difference in cpm readings for the same fish species, and amongst different fish species including dorade, salmon and seabass, spiked with sulfathiazole at the same concentration level (ANOVA, overall F-critical $3.35>$ F-calculated 1.99) with RSD $<10 \%$. Similar observations were made for the other

Table 5 Repeatability study at MRL, 0.5 MRL or concentration $<0.5$ MRL

\begin{tabular}{|c|c|c|c|c|c|}
\hline Family & Compound & Spiking concentration ( $\mu \mathrm{g} / \mathrm{kg})$ & Mean cpm & $S D_{r}$ & $\mathrm{RSD}_{\mathrm{r}}(\%)$ \\
\hline \multirow[t]{2}{*}{ Tetracyclines } & Chlortetracycline & $25 \mu \mathrm{g} / \mathrm{kg}(0.25 \mathrm{MRL})$ & 1207.0 & 118.2 & 9.8 \\
\hline & Oxytetracycline & $100 \mu \mathrm{g} / \mathrm{kg}(\mathrm{MRL})$ & 1270.06 & 98.41 & 7.75 \\
\hline \multirow[t]{2}{*}{ Macrolides } & Erythromycin A & $100 \mu \mathrm{g} / \mathrm{kg}(0.5 \mathrm{MRL})$ & 1762.4 & 110.4 & 6.3 \\
\hline & & $200 \mu \mathrm{g} / \mathrm{kg}(\mathrm{MRL})$ & 1478.1 & 41.2 & 2.8 \\
\hline \multirow[t]{2}{*}{$\beta$-Lactams } & Penicillin G & $25 \mu \mathrm{g} / \mathrm{kg}(0.5 \mathrm{MRL})$ & 1285.6 & 89.3 & 6.9 \\
\hline & & $50 \mu \mathrm{g} / \mathrm{kg}(\mathrm{MRL})$ & 648.5 & 62.7 & 9.7 \\
\hline \multirow[t]{2}{*}{ Aminoglycosides } & Streptomycin & $250 \mu \mathrm{g} / \mathrm{kg}(0.5 \mathrm{MRL})$ & 1125.8 & 112.7 & 10.01 \\
\hline & & $500 \mu \mathrm{g} / \mathrm{kg}(\mathrm{MRL})$ & 1110.5 & 127.2 & 11.5 \\
\hline \multirow[t]{2}{*}{ Sulfonamides } & Sulfathiazole & $25 \mu \mathrm{g} / \mathrm{kg}(0.25 \mathrm{MRL})$ & 922.2 & 80.1 & 8.7 \\
\hline & & $100 \mu \mathrm{g} / \mathrm{kg}(\mathrm{MRL})$ & 706.5 & 8.6 & 1.2 \\
\hline
\end{tabular}

$S D_{r}$, standard deviation under repeatability conditions, $R S D_{r}$, relative standard deviation under repeatability conditions, Mean $c p m$ average of counts per minute under reproducibility conditions 
Table 6 Repeatability in the detection of sulfathiazole at $25 \boldsymbol{\mu g} / \mathbf{k g}$ for selected fish samples

\begin{tabular}{llll}
\hline Parameter & \multicolumn{3}{l}{$\begin{array}{l}\text { Fish samples spiked with sulfathiazole } \\
\text { at } \mathbf{2 5} \boldsymbol{\mu} \mathbf{g} / \mathbf{k g}, \mathbf{c p m}\end{array}$} \\
\cline { 2 - 4 } & Dorade & Salmon & Seabass \\
\hline & 989 & 914 & 735 \\
& 815 & 969 & 780 \\
& 862 & 886 & 976 \\
& 876 & 1015 & 896 \\
& 782 & 932 & 890 \\
& 934 & 1075 & 978 \\
& 985 & 930 & 976 \\
& 877 & 1070 & 898 \\
Average & 863 & 935 & 975 \\
SD & 986 & 890 & 976 \\
RSD & 896.9 & 961.6 & 908 \\
\hline
\end{tabular}

antimicrobial agents, whose summarized results are presented in Table 5.

\section{Reproducibility of the method}

The reproducibility studies were performed by two different researchers following the same Charm II protocol on selected fish species, spiked with different antimicrobial agents and evaluated by means of intra-day and inter-day coefficient of variations. The reproducibility study characterized by the relative standard deviation (\%RSD) was satisfactory with a precision of less than $15.3 \%$ for the different antimicrobial drugs (tetracyclines, macrolides, $\beta$-lactams, aminoglycosides, and sulfonamides) spiked in blank fish samples at MRL, 0.5 MRL or concentration less than 0.5 MRL and studied under reproducibility conditions $(n \geq 6)$. The coefficient of variation calculated as percentage relative standard deviation (\%RSD) for tetracyclines (chlortetracycline and oxytetracycline) was 7.2 to $11.4 \%$; macrolides (erythromycin A) ranged from 5.8 to $8.9 \%$; $\beta$-lactams (penicillin $\mathrm{G}$ ) from 10.4 to $11.2 \%$; aminoglycosides from 8.9 to $15.1 \%$ and sulfonamides (sulfathiazole) from 2.8 to $8.3 \%$ as indicated in Table 7 .

An elaborate presentation of some results of the reproducibility studies performed by two different researchers following the same Charm II protocol on selected fish species, spiked with oxytetracycline at a concentration level of $100 \mu \mathrm{g} / \mathrm{kg}$, is presented in Table 8. A comparison of the results obtained by the two researchers for the same fish species showed no significant difference; and the overall analysis showed no significant difference in the cpm results for the different fish species including seabass, pangasius and salmon (ANOVA, F-critical 4.1 > F-calculated 0.64), with $\mathrm{RSD}<10 \%$, which further demonstrates the technique's reproducibility with little matrices interference. Similar observations were made for the other antimicrobial compounds, whose summarized results are presented in Table 7.

\section{Robustness of the method}

Analysis of batches of many samples often require a couple of hours before completion; and there is likely to be a time interval between the first and last analysis of the processed samples. In the robustness testing of the Charm II assay, the effect of variation in reading time interval for processed samples was studied. Robustness testing was performed on samples spiked with $50 \mu \mathrm{g} /$ $\mathrm{kg}$ amoxicillin and analysed on the $\beta$-lactams channel immediately after mixing $(0 \mathrm{~h})$ and after $14 \mathrm{~h}$. The control point for $\beta$-lactams was set at 1530 , and the robustness results are presented in Table 9.

From Table 9, it is evident that there was no significant difference in the cpm for both pangasius and dorade

Table 7 Reproducibility study at MRL, 0.5 MRL or concentration $<0.5$ MRL

\begin{tabular}{|c|c|c|c|c|c|}
\hline Family & Compound & Spiking concentration ( $\mu \mathrm{g} / \mathrm{kg})$ & Mean cpm & $S D_{r}$ & $\mathrm{RSD}_{\mathbf{r}}(\%)$ \\
\hline \multirow[t]{2}{*}{ Tetracyclines } & Chlortetracycline & $25 \mu \mathrm{g} / \mathrm{kg}(0.25 \mathrm{MRL})$ & 1224.5 & 139.2 & 11.4 \\
\hline & Oxytetracycline & $100 \mu \mathrm{g} / \mathrm{kg}(\mathrm{MRL})$ & 1277 & 92.6 & 7.2 \\
\hline \multirow[t]{2}{*}{ Macrolides } & Erythromycin A & $100 \mu \mathrm{g} / \mathrm{kg}(0.5 \mathrm{MRL})$ & 1748.5 & 156.1 & 8.9 \\
\hline & & $200 \mu \mathrm{g} / \mathrm{kg}(\mathrm{MRL})$ & 1456.5 & 83.9 & 5.8 \\
\hline \multirow[t]{2}{*}{$\beta$-Lactams } & Penicillin G & $25 \mu \mathrm{g} / \mathrm{kg}(0.5 \mathrm{MRL})$ & 1204.9 & 135.0 & 11.2 \\
\hline & & $50 \mu \mathrm{g} / \mathrm{kg}(\mathrm{MRL})$ & 702.1 & 73.0 & 10.4 \\
\hline \multirow[t]{2}{*}{ Aminoglycosides } & Streptomycin & $250 \mu \mathrm{g} / \mathrm{kg}(0.5 \mathrm{MRL})$ & 1110.6 & 98.7 & 8.9 \\
\hline & & $500 \mu \mathrm{g} / \mathrm{kg}(\mathrm{MRL})$ & 1132.6 & 171.4 & 15.1 \\
\hline \multirow[t]{2}{*}{ Sulfonamides } & Sulfathiazole & $25 \mu \mathrm{g} / \mathrm{kg}(0.25 \mathrm{MRL})$ & 943.7 & 78.1 & 8.3 \\
\hline & & $100 \mu \mathrm{g} / \mathrm{kg}(\mathrm{MRL})$ & 647.1 & 18.1 & 2.8 \\
\hline
\end{tabular}

$S D_{r}$ standard deviation under reproducibility conditions, $R S D_{r}$ relative standard deviation under reproducibility conditions 
Table 8 Reproducibility in the detection of oxytetracycline at $100 \mu \mathrm{g} / \mathrm{kg}$ for selected fish samples

\begin{tabular}{lll}
\hline Fish sp. & Researcher 1, cpm & Researcher 2, cpm \\
\hline Seabass & 1176 & 1296 \\
& 1177 & 1265 \\
& 1295 & 1177 \\
& 1334 & 1281 \\
& 1127 & 1166 \\
& 1341 & 1417 \\
& 1170 & 1460 \\
& 1261 & 1074 \\
Pangasius & 1371 & 1361 \\
& 1201 & 1335 \\
& 1225 & 1185 \\
Salmon & 1166 & 1223 \\
& 1094 & 1224 \\
Average & 1408 & 1407 \\
RSD & 1408 & 1405 \\
& 1307 & 1307 \\
& 1378 & 1299 \\
& 1298 & 1310 \\
& 1274 & 1311 \\
& 1313 & 1279 \\
& 1266.2 & 1289.1 \\
& 1176 & 1296 \\
& 94.6 & 96.2 \\
& 0.07 & 0.07 \\
& & \\
& &
\end{tabular}

spiked with $50 \mu \mathrm{g} / \mathrm{kg}$ of beta-lactams and read after 0 or $14 \mathrm{~h}$ (ANOVA, F-critical 4.3>F- calculated 0.2) confirming the robustness of the method, in regard to variation in reading time intervals of the processed samples. A comparison of cpm for blank fish samples for both pangasius and dorade after 0 and $14 \mathrm{~h}$, also showed that there was no significant difference between counts since ANOVA F-critical 4.9>F-calculated 0.2. The combined results of these studies demonstrate that the Charm II technique is quite robust for the analysis of antimicrobials in fish.

\section{Specificity and cross reactivity of the technique}

The cross reactivity analysis was carried out in order to determine whether the presence of non-target drugs may lead to false identification of the target drug; or whether the identification of the target analyte may be hindered by the presence of one or more interferences. Representative blank fish samples were spiked with different antimicrobial drugs at known concentration levels higher than those likely to interfere with the identification of the analyte of interest, and then analysed using the respective Charm II protocol for the target drug. The aminoglycosides (spectinomycin, neomycin B and paromomycin) were analysed using the macrolide channel (meant for erythromycin A, tilmicosin and tylosin A). A standard mix containing aminoglycosides (spectinomycin, neomycin B and paromomycin) was used to spike different fish samples at 150,300 and $500 \mu \mathrm{g} / \mathrm{kg}$ level, and the results are presented in Table 10.

Results show that although the macrolides which were the targeted antimicrobials tested positive (samples spiked with erythromycin A at $200 \mu \mathrm{g} / \mathrm{kg}$, gave

Table 9 Robustness testing using amoxicillin spiked at $50 \mu \mathrm{g} / \mathrm{kg}$ for selected fish samples

\begin{tabular}{|c|c|c|c|c|c|}
\hline \multirow[t]{2}{*}{ Time } & \multirow[t]{2}{*}{ Run } & \multicolumn{2}{|c|}{ Spiked at $50 \mu \mathrm{g} / \mathrm{kg}$} & \multicolumn{2}{|l|}{ Non spiked } \\
\hline & & Pangasius, cpm & Dorade, cpm & Blanks, cpm & Fish species \\
\hline \multirow[t]{6}{*}{ Results at $0 \mathrm{~h}$} & 1 & 1019 & 1069 & 2433 & Pangasius \\
\hline & 2 & 1024 & 959 & 2398 & Pangasius \\
\hline & 3 & 1017 & 1019 & 2399 & Pangasius \\
\hline & 4 & 1201 & 1069 & 2064 & Dorade \\
\hline & 5 & 1155 & 1033 & 2200 & Dorade \\
\hline & 6 & 1020 & 1067 & 2109 & Dorade \\
\hline \multirow[t]{6}{*}{ Results after $14 \mathrm{~h}$} & 7 & 1120 & 1120 & 2399 & Pangasius \\
\hline & 8 & 1059 & 1080 & 2064 & Pangasius \\
\hline & 9 & 1260 & 1195 & 2399 & Pangasius \\
\hline & 10 & 1011 & 1113 & 2068 & Dorade \\
\hline & 11 & 1089 & 1089 & 2210 & Dorade \\
\hline & 12 & 1099 & 1092 & 2205 & Dorade \\
\hline Average & & 1089.5 & 1075.4 & 2245.7 & \\
\hline SD & & 81.6 & 57.9 & 150.8 & \\
\hline RSD & & 0.07 & 0.05 & 0.07 & \\
\hline
\end{tabular}


Table 10 Specificity and cross reactivity tests using the Macrolides kit

\begin{tabular}{|c|c|c|c|c|c|c|}
\hline Blanks cpm & $\begin{array}{l}\text { AMGL spiked } \\
\text { at } 150 \mu \mathrm{g} / \mathrm{kg} \text {, } \\
\text { Salmon } \mathrm{cpm}\end{array}$ & $\begin{array}{l}\text { AMGL spiked } \\
\text { at } 300 \mu \mathrm{gg} / \mathrm{kg} \text {, } \\
\text { Salmon } \mathrm{cpm}\end{array}$ & $\begin{array}{l}\text { AMGL spiked } \\
\text { at } 500 \mu \mathrm{g} / \mathrm{kg}, \\
\text { Pangasius cpm }\end{array}$ & $\begin{array}{l}\text { AMGL spiked } \\
\text { at } 150 \mu \mathrm{g} / \mathrm{kg} \text {, } \\
\text { Catfish cpm }\end{array}$ & $\begin{array}{l}\text { AMGL spiked } \\
\text { at } 300 \mu \mathrm{\mu g} / \mathrm{kg} \text {, } \\
\text { Catfish cpm }\end{array}$ & $\begin{array}{l}\text { AMGL spiked } \\
\text { at } 500 \mu \mathrm{g} / \mathrm{kg} \text {, Trout } \\
\text { cpm }\end{array}$ \\
\hline 5377 & 5097 & 5239 & 5239 & 5536 & 5511 & 4694 \\
\hline 5538 & 4860 & 4931 & 4931 & 5224 & 5393 & 5262 \\
\hline 5538 & 5106 & 4800 & 5034 & 5223 & 5803 & 5412 \\
\hline 5076 & 4703 & 4900 & 5351 & 4966 & 5558 & 5686 \\
\hline 5571 & 5039 & 4950 & 5121 & 5236 & 5807 & 5728 \\
\hline
\end{tabular}

AMGL aminoglycosides standard mix containing spectinomycin, neomycin $\mathrm{B}$ and paromomycin

Table 11 Specificity and cross reactivity tests with mixed standards of different antimicrobial using the Aminoglycosides kit

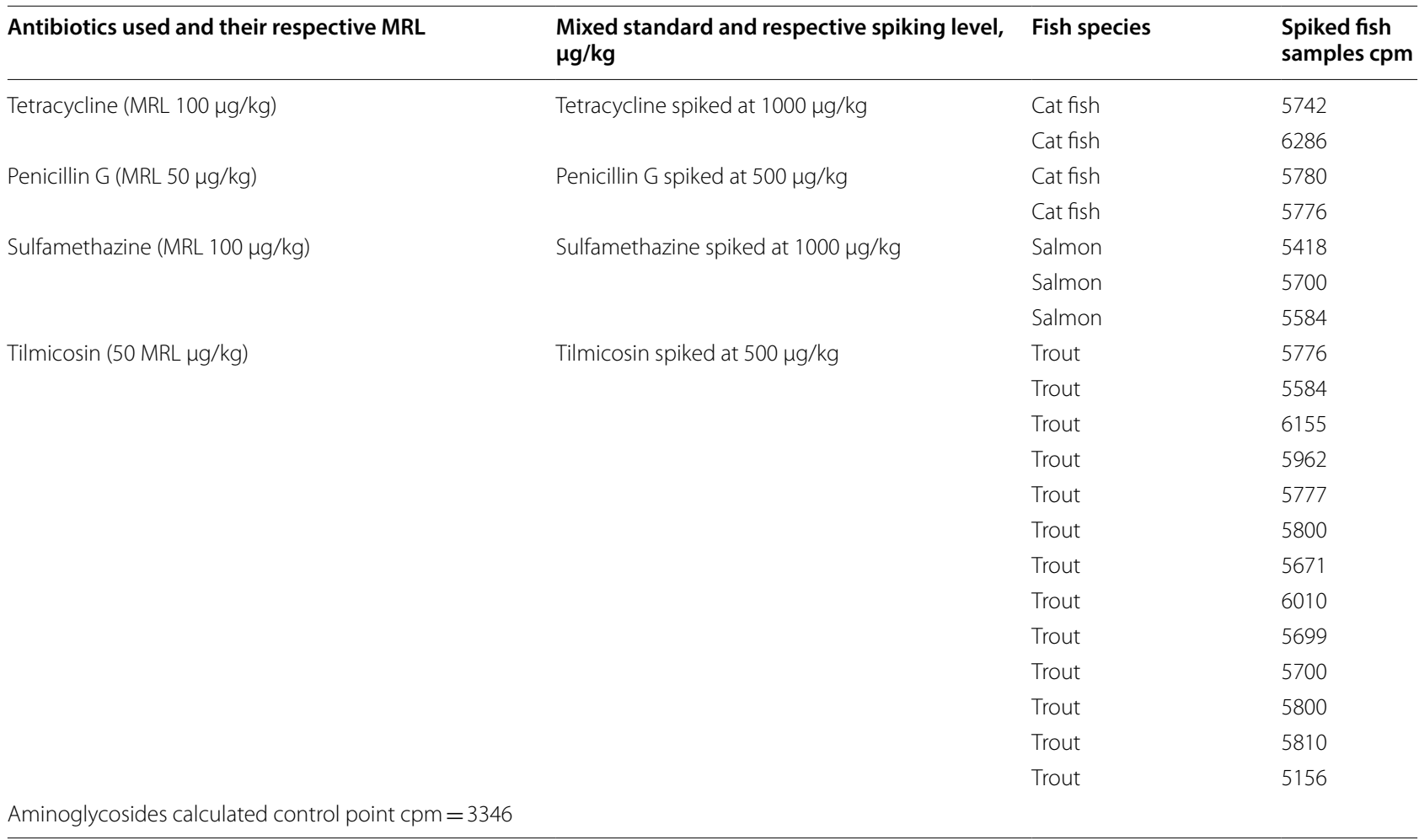

$1478 \mathrm{cpm})$, the non-target aminoglycosides intentionally analyzed on the same channel, tested negative since in all cases the observed cpm were above the set control point of the macrolides of 2118 . In similar studies, cross reactivity was further investigated by spiking residue-free, blank fish samples with high concentrations (10 MRL) of antimicrobial substances belonging to other groups (sulfonamides, $\beta$-lactams, macrolides, and tetracyclines) and were analysed on the aminoglycosides channel; and the results are presented in Table 11.
The results of these studies also showed that no residues of the non-target drugs (tetracycline, penicillin G, sulfamethazine and tilmicosin) could be detected using the aminoglycosides channel as shown in Table 11; whereas samples spiked with spectinomycin at $500 \mu \mathrm{g} /$ $\mathrm{kg}$ tested positive with $1110 \mathrm{cpm}$ when analysed under the same channel. All spiked samples tested negative and the non-target compounds could not be detected even at high concentration (10 MRL). Similar observations were made when utilizing the Biochip Array 
Technology assay, where none of the tested antimicrobials could be detected under cross-reactivity studies [28].

\section{Conclusions}

The Charm II radio receptor assay technique was successfully validated for screening residues of tetracyclines, sulfonamides, $\beta$-lactams, aminoglycosides and macrolides in different aquaculture fish species. The Charm II technique can detect tetracycline and chlortetracycline at $25 \mu \mathrm{g} / \mathrm{kg}(0.25 \mathrm{MRL})$ and oxytetracycline at $100 \mu \mathrm{g} / \mathrm{kg}$ (MRL) for different fish species including, cat fish, trout, salmon, seabass, tilapia, lingue, dorade, and pangasius, with $100 \%$ detection. The sulfonamides including sulfadimethoxine, sulfamerazine, sulfadiazine, sulfathiazole could be detected at $25 \mu \mathrm{g} / \mathrm{kg}(0.25 \mathrm{MRL})$ for all fish species involved in the study, with the exception of catfish, pangasius, and lingue, which gave high counts for the blank samples. Results for the macrolides analysis, showed that erythromycin $\mathrm{A}$, tilmicosin, and tylosin $\mathrm{A}$, could be detected at $100 \mu \mathrm{g} / \mathrm{kg}(0.5 \mathrm{MRL}), 100 \mu \mathrm{g} / \mathrm{kg}(2 \mathrm{MRL})$ and $100 \mu \mathrm{g} /$ $\mathrm{kg}$ (MRL), respectively, for the different fish species. Whereas, the $\beta$-lactams including penicillin G, ampicillin, amoxicillin, oxacillin, dicloxacillin and cloxacillin were detected at $25 \mu \mathrm{g} / \mathrm{kg}(0.5 \mathrm{MRL}), 50 \mu \mathrm{g} / \mathrm{kg}$ (MRL), $50 \mu \mathrm{g} / \mathrm{kg}$ (MRL), $300 \mu \mathrm{g} / \mathrm{kg}$ (MRL), $300 \mu \mathrm{g} / \mathrm{kg}$ (MRL) and $300 \mu \mathrm{g} / \mathrm{kg}$ (MRL), respectively. Under the aminoglycosides analysis, streptomycin was detected at $25 \mu \mathrm{g} / \mathrm{kg}(0.05 \mathrm{MRL})$ for all fish species involved in the study. Interestingly, the technique can detect a broader range of antimicrobials other than only the compounds specified in the Charm II assay kit. In addition, all antimicrobial compounds involved in the study could be successfully detected using the Charm II assay at $100 \%$ rate, with the exception of dicloxacillin, cloxacillin, sulfamethazine and sulfathiazole that exhibited false negative rates of 4.5, 5.0, 3.4 and 5.0\%, respectively. Moreover, these false negative rates fall within the $5 \%$ requirement of the EU decision 2002/657, and therefore, the validation results are satisfactory.

Robustness studies showed that there was no significant difference between results for counts of the same samples read immediately or after $14 \mathrm{~h}$ of addition of the scintillation fluid. In addition, no evidence of crossreactivity was observed among the targeted antimicrobial compounds on interchanging the antimicrobial analysis channels. The results of this validation study prove the robustness, specificity, reliability and precision of the Charm II radio receptor assay technique in the detection of various antimicrobials residues in different fish species. The study confirms the suitability of the Charm II technique as a valuable screening tool for detection of antimicrobial residues in a variety of fish species; and its applicability for the rapid evaluation of the quality of aquaculture products for safety and trade purposes.

\section{Supplementary information}

Supplementary information accompanies this paper at https://doi. org/10.1186/s13065-020-00684-4.

Additional file 1: Table S1a. List of analytical standards used for spiking Table S1b. Limits of quantification and detection from Charm II assays and published results.

\section{Abbreviations}

ANOVA: One-way analysis of variance; CCB: Detection capability; CP: Control point; CPM: Counts per minute; EU: European Union; FAO: Food and Agriculture Organization; IAEA: International Atomic Energy Agency; ILVO: Flanders Research Institute for Agriculture, Fisheries and Food; MRL: Maximum residue limit; MSU: Multi antimicrobial standard; RSD: Relative standard deviation; SD: Standard deviation; UNBS: Uganda National Bureau of Standards.

\section{Acknowledgements}

The study was performed with support from the International Atomic Energy Agency (IAEA) program on Development and Strengthening of Radio-Analytical and Complementary Techniques to Control Residues of Veterinary Drugs and Related Chemicals in Aquaculture Products, Vienna Austria. The authors would also like to acknowledge support from the Uganda National Bureau of Standards, Kampala-Uganda; Institute of Medical Research and Medicinal Plant Studies, Yaounde, Cameroon; Flanders Research Institute for Agriculture, Fisheries and Food, Melle-Belgium and Department of Chemistry, Makerere University Kampala, Uganda. We are also very grateful to Charm Sciences Inc. for providing the Charm II test reagents and kits.

\section{Authors' contributions}

AKM, WR, MFKG and JS participated in experimental design and coordination of laboratory activities. AKM, MFKG and WR carried out the sampling, sample preparation and analysis. WR, JJTT, AKM and ET participated in data analysis. AKM, ET, MH and SAN wrote the manuscript. All authors participated in manuscript review. All authors read and approved the final manuscript.

\section{Funding}

The work was financially supported by the International Atomic Energy Agency (IAEA) program on Development and Strengthening of RadioAnalytical and Complementary Techniques to Control Residues of Veterinary Drugs and Related Chemicals in Aquaculture Products. The work was partially supported by Charm Sciences Inc. who provided all the Charm II test reagents and kits used in the study.

Availability of data and materials

All supporting information including table of results and detailed methods is available upon request.

\section{Competing interests}

The authors declare that they have no competing interests.

\section{Author details}

${ }^{1}$ Uganda National Bureau of Standards, Headquarters. Plot 2-12 Bypass Link, Industrial \& Business Park, Kyaliwajala Road, P.O. Box 6329, Kampala, Uganda.

${ }^{2}$ Institute of Medical Research and Medicinal Plant Studies, P.O. Box 6163, Yaounde, Cameroon. ${ }^{3}$ International Atomic Energy Agency (IAEA), Vienna International Centre, P. O. Box 100, 1400 Vienna, Austria. ${ }^{4}$ Flanders Research Institute for Agriculture, Fisheries and Food (ILVO), Technology and Food Science Unit, Brusselsesteenweg 370, 9090 Melle, Belgium. ${ }^{5}$ Department of Chemistry, College of Natural Sciences, Makerere University, P.O. Box, 7062, Kampala, Uganda. 
Received: 12 December 2019 Accepted: 9 April 2020

Published online: 25 April 2020

\section{References}

1. FAO (2010) The State of World Fisheries and Aquaculture 2010. FAO Fisheries and Aquaculture Department, Rome

2. HLPE (2014) Sustainable fisheries and aquaculture for food security and nutrition. A report by the High Level Panel of Experts on Food Security and Nutrition of the Committee on World Food Security, Rome 2014

3. Tidwell HJ, Allan GL (2001) Fish as food: aquaculture's contribution, Ecological and economic impacts and contributions of fish farming and capture fisheries. EMBO Rep 2(11):958-963

4. Serrano PH (2005) Responsible use of antibiotics in aquaculture. Fisheries Technical Paper 469, Food and Agriculture Organization of the United Nations (FAO), Rome

5. Wardle R, Boetner A (2012) Health management tools from a manufacturer's point of view. In: Bondad-Reantaso MG, Arthur JR, Subasinghe RP. Improving biosecurity through prudent and responsible use of veterinary medicines in aquatic food production, FAO Fisheries and Aquaculture Technical Paper No. 547: 147-153. Rome

6. FAO (1997) Joint Group of Experts on the Scientific Aspects of Marine Environment Protection, GESAMP, (IMO/FAO/UNESCO-IOC/WMO/WHO/ IAEA/UN/UNEP), Reports and Studies No. 65, Rome

7. Love DC, Rodman S, Neff RA, Nachman KE (2010) Veterinary drug residues in seafood inspected by the European Union, United States, Canada, and Japan from 2000 to 2009. Environ Sci Technol. 45(17):7232-7240

8. Olatoye IO, Basiru A (2013) Antibiotic usage and oxytetracycline residue in African Catfish (Clarias gariepinus) in Ibadan, Nigeria. World J Fish Mar Sci 5(3):302-309

9. Huang T, Du XW, Marshall MR, Wei Cl (1997) Determination of oxytetracycline in raw and cooked channel catfish by capillary electrophoresis. J Agric Food Chem 45(7):2602-2605

10. Fritz JW, Zuo Y (2007) Simultaneous determination of tetracycline, oxytetracycline, and 4-epitetracycline in milk by high-performance liquid chromatography. Food Chem 105(3):1297-1301

11. Granados CF, Rodriguez C (2017) Tetracyclines in food and feeding tuffs: from regulation to analytical methods, bacterial resistance, and environmental and health implications. J Anal Methods Chem. 2017:1315497

12. Commission European (2010) Commission Regulation (EU) No 29 37/2010 of 22 December 2009 on pharmacologically active substances and their classification regarding maximum residue limits in foodstuffs of animal origin. Off J Eur Union L 15:1-72

13. Marshall BM, Levy SB (2011) Food animals and antimicrobials: impacts on human health. Clin Microbiol Rev 2:718-733

14. Amit R, Sahu NP, Subodh G, Md Aklakur. Prospects of medicated feed in aquaculture. Nutri Food Sci Int J. 3(4): 555617

15. FAO (2003) Joint FAO/OIE/WHO Expert Workshop on non-human antimicrobial usage and antimicrobial resistance: scientific assessment, Geneva, December $1-5$

16. Cabello FC (2006) Heavy use of prophylactic antibiotics in aquaculture: a growing problem for human and animal health and for the environment. Environ Microbiol 8(7):1137-1144

17. Alderman DJ, Hastings TS (2003) Antibiotic use in aquaculture: development of antibiotic resistance-potential for consumer health risks. Int J Food Sci Technol 33(2):139-155
18. Samanidou VF, Evaggelopoulou EN (2007) Analytical strategies to determine antibiotic residues in fish. J Sep Sci 30(16):2549-2569. https://doi. org/10.1002/jssc.200700252

19. Heuer OE, Kruse H, Grave K, Collignon P, Karunasagar I, Angulo FJ (2009) Human health consequences of use of antimicrobial agents in aquaculture. Clin Infect Dis 49(8):1248-1253

20. WHO (2011) Tackling antibiotic resistance from a food safety perspective in Europe, World Health Organization Regional Office for Europe, DK-2100 Copenhagen, Denmark

21. Charm Sciences (2014) The Charm II radio receptor tests for detection of antimicrobials, Charm Sciences Inc, Lawrence, MA 01843-1032 USA

22. Kwon SI, Owens G, Ok YS, Lee DB, Jeon WT, Kim JG, Kim KR (2011) Applicability of the Charm II system for monitoring antibiotic residues in manure-based composts. Waste Manag 31(1):39-44

23. European Commission Decision (2002) Commission Decision 2002/657/ EC Implementing Council Directive 96/23/EC concerning the performance of analytical methods and the interpretation of results. http:// ec.europa.eu/food/chemicalsafety/residues/lab analysis en.htm. Accessed 10 Sept 2019

24. Charm SE, Chi R (1988) Microbial receptor assay for rapid detection and identification of seven families of antimicrobial drugs in milk: collaborative study. J Assoc Off Anal Chem 71(2):304-316

25. Korsrud OG, Papich GM, Fesser CEA, Salibury DCC, Macneil DJ (1995) Laboratory testing of the Charm II test receptor assays and the Charm Farm test with tissues and fluids from hogs fed sulfamethazine, chlortetracycline, and Penicillin G. J Food Prot 59(2):161-166

26. EU Guidelines (2010) Community Reference Laboratories Residues (CRLs), 20/1/2010, Guidelines for the validation of screening methods for residues of veterinary medicines

27. Masud Rana AYKM, Talukdar SU, Md Nabi M, Md Islam H, Islam MJ, Saifullah ASM (2018) Validation of a commercial enzyme-linked immunosorbent assay for screening tetracycline residues in foods of animal origin from the perspective of Bangladesh. J Pharm Res Int 24(6):1-9

28. Gaudin V, Hedou C, Soumet C, Verdon E (2016) Evaluation and validation of a multi-residue method based on biochip technology for the simultaneous screening of six families of antibiotics in muscle and aquaculture products. Food Addit Contam Part A 33(3):403-419

29. Rezk RM, Riad MS, Khattab IF, Marzouk MH (2015) Multi-residues determination of antimicrobials in fish tissues by HPLC-ESI-MS/MS method. J Chromatogr B 978-979:103-110

30. Cháfer-Pericás C, Maquieira Á, Puchades R, Company B, Miralles J, Moreno A (2010) Multiresidue determination of antibiotics in aquaculture fish samples by HPLC-MS/MS. Aquac Res 41:217-225

31. Guidi RL, Santos AF, Robeiro SRAC, Fernandes C, Silva HML, Gloria BAM (2017) A simple, fast and sensitive screening LC-ESI-MS/MS method for antibiotics in fish. Talanta 163:85-93

\section{Publisher's Note}

Springer Nature remains neutral with regard to jurisdictional claims in published maps and institutional affiliations.

Ready to submit your research? Choose BMC and benefit from

- fast, convenient online submission

- thorough peer review by experienced researchers in your field

- rapid publication on acceptance

- support for research data, including large and complex data types

- gold Open Access which fosters wider collaboration and increased citations

- maximum visibility for your research: over 100M website views per year

At BMC, research is always in progress.

Learn more biomedcentral.com/submissions 